\title{
Soil compaction under the wheel of a sprayer
}

\author{
Nicoleta Ungureanu ${ }^{1}$, Valentin Vlăduț ${ }^{2 *}$ and Dan $\mathrm{Cujbescu}^{2}$ \\ ${ }^{1}$ Politehnica University of Bucharest, Department of Biotechnical Systems, Splaiul Independentei nr. \\ 313, sector 6, Romania \\ ${ }^{2}$ National Institute of Research - Development for Machines and Installations Designed to \\ Agriculture and Food Industry - INMA Bucharest, Ion Ionescu de la Brad nr. 6, sector 1, Romania
}

\begin{abstract}
Soil degradation by artificial compaction is recognized by the European Union as a major environmental and agricultural problem. Artificial compaction has worsened with the intensification of mechanized agriculture where heavier machinery is used, often moving on soils with high moisture. Experimental research was designed to determine the influence of five wheel loads and tire inflation pressures, on the contact area, the shape of footprint and the contact pressure, under the wheel of a machine for high accuracy application of phytosanitary treatments in orchards. It was found that the only situation when compaction does not occur is when the tank is empty $(2.45 \mathrm{kN}$ wheel load), at lowest tire inflation pressure of $100 \mathrm{kPa}$. Subsoil compaction (at 0.3-0.4 m) occurs when the sprayer machine's tank is filled with different amounts of liquid. With empty tank, the sprayer only causes topsoil compaction.
\end{abstract}

\section{Introduction}

Artificial compaction is a large scale, negative phenomenon that raises serious concerns over the sustainability of soils. Compaction develops as a consequence of using larger agricultural machines, increased number of soil works, short rotations and intensive pasturing of livestock [1]. Each mechanized agricultural work, from the preparation of the soil for crop establishment until its harvest, is involved in increasing the degree of artificial compaction of the agricultural soil [2].

Consequences of the artificial compaction on soil properties and especially on soil fertility are strongly negative. Compaction reduces the biota activity, soil porosity and permeability. At the same time, soil strength increases and its structure is broken. In terms of environment, there are increased risks of erosion, surface landslides, pesticides and nutrients flow into groundwater. Some agronomic consequences of soil compaction are: reduced plant capacity to assimilate the nutrients and water, restricted root penetration into the subsoil, decline in crop yields, and last but not least, high resistance to soil processing and high fuel consumption [2-5].

It has been reported that there are 68 mil. hectares of compacted soil globally only because of the traffic of agricultural machinery [6]. In Europe, over 33 mil. hectares of soil are compacted. Eastern Europe has 20 mil. hectares of compacted soil $(37.5 \%$ of its

\footnotetext{
* Corresponding author: valentin_vladut@yahoo.com
} 
agricultural soil) [7]. In 2017, Romania had reported a total of 6.5 mil. hectares of arable soils artificially compacted and 2 mil. hectares affected by natural compaction [8].

The artificial compaction of agricultural soil is due to a variety of factors that are related to both the characteristics of the agricultural machinery and work (wheel load; tire inflation pressure; footprint area which in turn has variable size and shape; the pressure on the soil or contact pressure; machinery speed; the number of passes; tire size; tire slippage) and the soil properties (soil moisture, soil type, texture, structure, and moisture) $[9,10]$.

Tire inflation pressure has a tremendous influence on the contact area and also on the contact pressure, the latter being also influenced by the wheel load [11, 12, 13]. Tire inflation pressure mostly influences the stress distribution up to $100 \mathrm{~mm}$ deep, and has a small influence on the stress distribution in the subsoil (below $300 \mathrm{~mm}$ ) [14].

Wheel load is dynamic, as it can act over the soil from a few seconds (for example, at soil-plowing tool interaction or load applied to the soil at the passage of the tire) and up to a few minutes (often found in forestry) [15]. Over the past three decades, larger agricultural machinery have been built, but this has inevitably increased wheel load without reducing the contact pressure to prevent or minimize the artificial compaction [16].

The intense use of heavy agricultural machinery leads to the distribution of stresses at greater depths in the soil. 10-15 tons/axle harvesters produce compaction of the soil under the arable layer (at $25 \mathrm{~cm}$ deep) [17]. To avoid compaction below the arable layer (0.2-0.3 $\mathrm{m}$ deep), wheel load should be under 4-6 tons on one axle, for wet mineral soil at tire inflation pressures of $50 \mathrm{kPa}$. For tandem tires, the limit is $8-10$ tons on wet soils. On dry soils, wheel load can be higher without causing subsoil compaction [18]. Repeated traffic of light agricultural vehicles on the same tracks with loads of less than 3 tons per axle produces subsoil compaction [19].

The contact pressure should be less than $100 \mathrm{kPa}$ during field works and $300-350 \mathrm{kPa}$ during transportation on field roads [20]. Contact pressure higher than $80 \mathrm{kPa}$ leads to soil compaction and and will prevent root development and plant growth [21]. One tractor pass with $0.15 \mathrm{MPa}$ contact pressure will have effects at the depth of $0.3-0.4 \mathrm{~m}$, and multiple passes have effects to $0.6 \mathrm{~m}$ depth [22].

Loads applied by the agricultural machinery are distributed to different soil depths, through the footprint between the soil and tire (Figure 1), resulting in artificial topsoil and /or subsoil compaction. Contact area is the part of the tire that is in contact with the soil. It is computed as ratio of the wheel load and the tire inflation pressure. If the agricultural machinery is stationary, the tire is still loaded but only statically, and in this case, the static contact area is the contact area between the tire and the rigid or deformable surface [23].

The larger the footprint, the contact pressure is smaller and the stress is distributed at lower depths in the soil, minimizing rut depth and the compaction intensity.
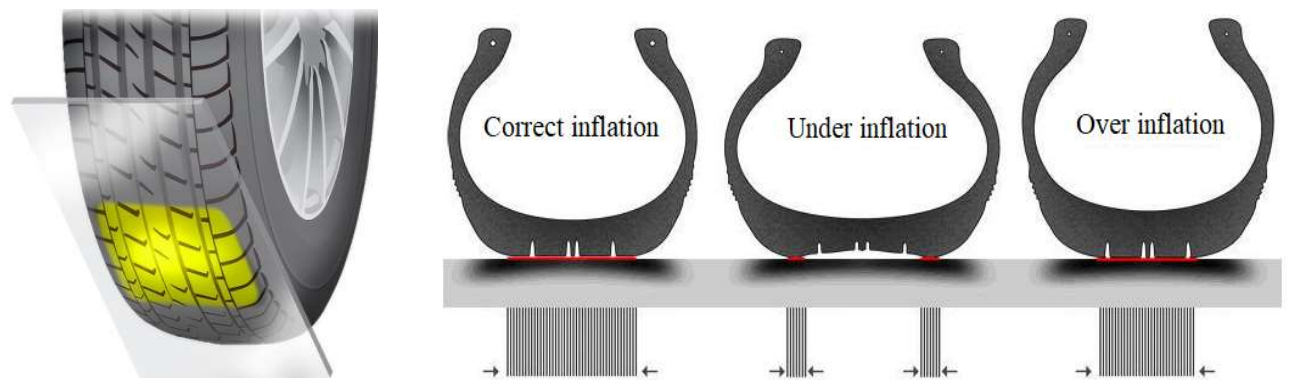

Fig. 1. Footprint detail and aspects at different tire inflation pressures [24, 25]

Tires are flexible, so the footprint can vary when the machinery is in motion than when it is static. In many studies, observations on the footprint were made in static experiments, 
in which footprint size and shape, and pressure distribution are mainly influenced by tire inflation pressure and by wheel load.

\section{Material and method}

Testing was carried out on an experimental field at INMA Bucharest. The aim was to determine the contact area under the influence of different wheel loads and tire air pressures.

It was tested the contact area and shape of footprint under the left wheel of the MSL sprayer machine for the high-precision application of phytosanitary treatments in fruit plantations, in aggregate with the Universal 445 tractor. Both the sprayer wheels and the front wheel of the tractor are equipped with Danubiana Superfront Tractor tires, size 6.0016 , profile F-2. The total weight of the spraying machine with the empty liquid tank is 4.9 $\mathrm{kN}(2.4517 \mathrm{kN}$ on each wheel).

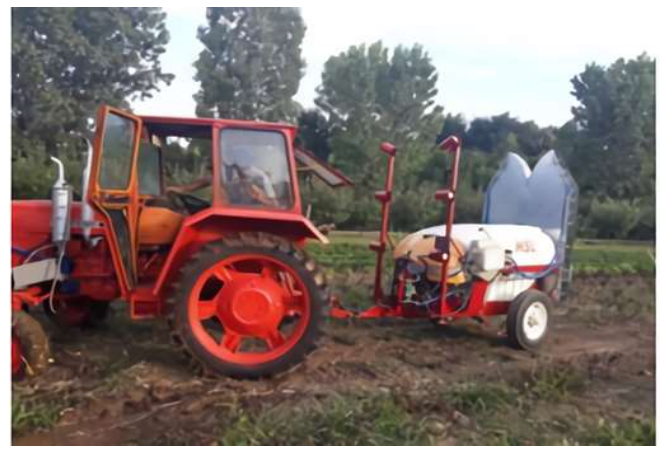

Fig. 2. U445 tractor in aggregate with MSL sprayer

Five sets of tests were carried out. In the first set, the tank was empty (wheel load 2.45 $\mathrm{kN}$ ), then it was progressively filled with 250 liters of water (wheel load $4.9 \mathrm{kN}$ ), 500 liters (wheel load $7.36 \mathrm{kN}$ ), 750 liters (wheel load $9.81 \mathrm{kN}$ ) and up to a maximum capacity of 1000 liters (wheel load $12.26 \mathrm{kN}$ ).

Wheel load was determined using the RW-10PRF weighing platform with electronic indicator. In each test, a compressor and a manometer were used to obtain five tire inflation pressures, from 100 to $300 \mathrm{kPa}$, in increments of $50 \mathrm{kPa}$.
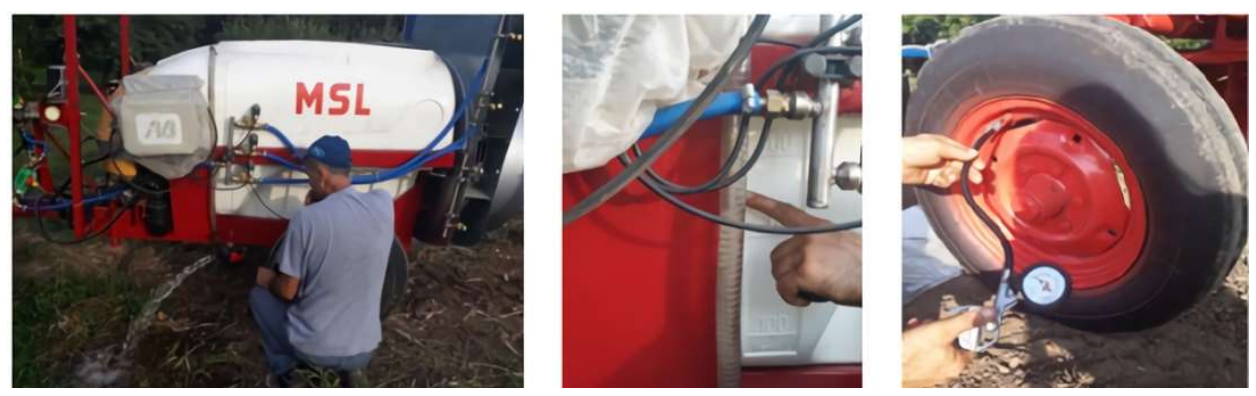

Fig. 3. Setting of wheel load and measuring tire inflation pressure during testing

Contact pressure between the wheel and the soil, as well as the contact area, were measured by the Tekscan pressure sensor (Figures 4 and 5) with dimensions $600 \times 500 \mathrm{~mm}$. For data acquisition, the VersaTek Handle electronic system and a laptop were used. 

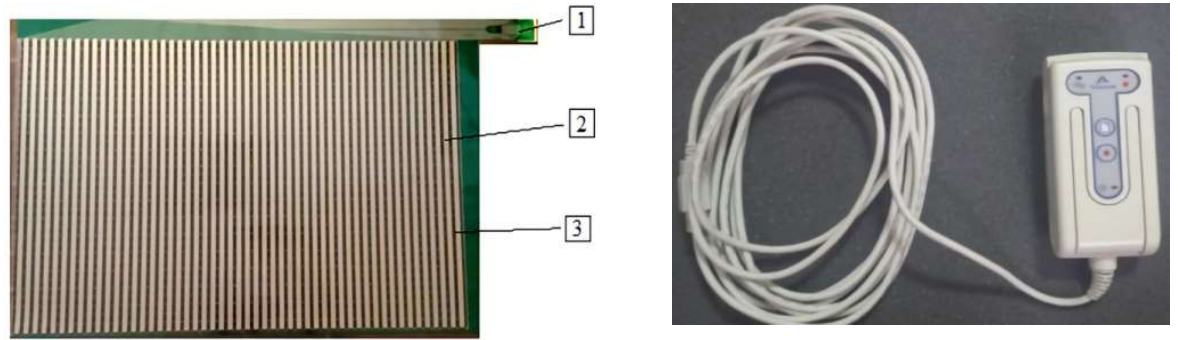

Fig. 4. Mesh-type Tekscan pressure sensor and VersaTek Handle data acquisition system 1 - connection to data acquisition system; 2 - sensels; 3 - connecting threads between sensels
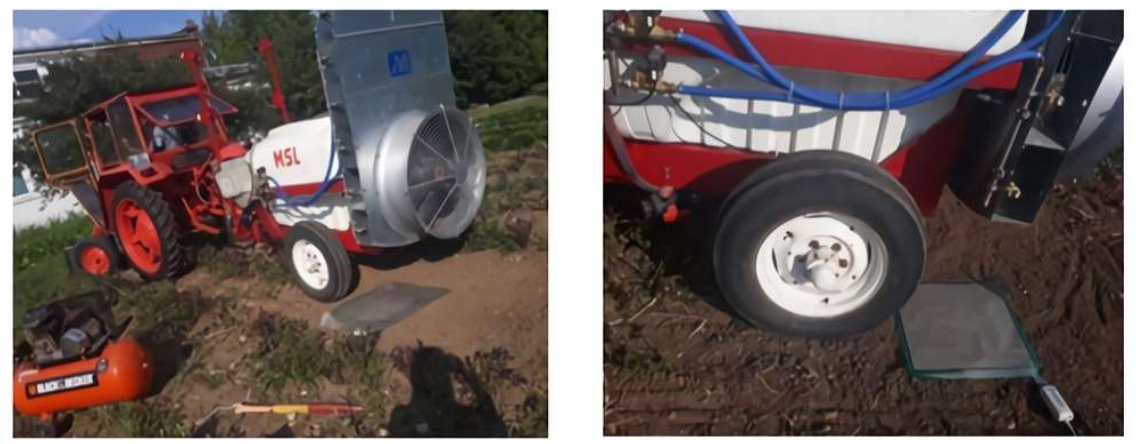

Fig. 5. Field preparation for testing and placement of the pressure sensor before wheel passing

During the tests, the tractor moved backwards (so its wheels did not cross the pressure sensor) and stopped when the wheel of the MSL spraying machine reached the surface of the sensor, allowing data saving in the I-Scan software.

Figure 6 shows how the sprayer's tire behaved with the tank loaded with 250 liters of water (wheel load $4.9 \mathrm{kN}$ ) at the tire inflation pressure of $100 \mathrm{kPa}$.
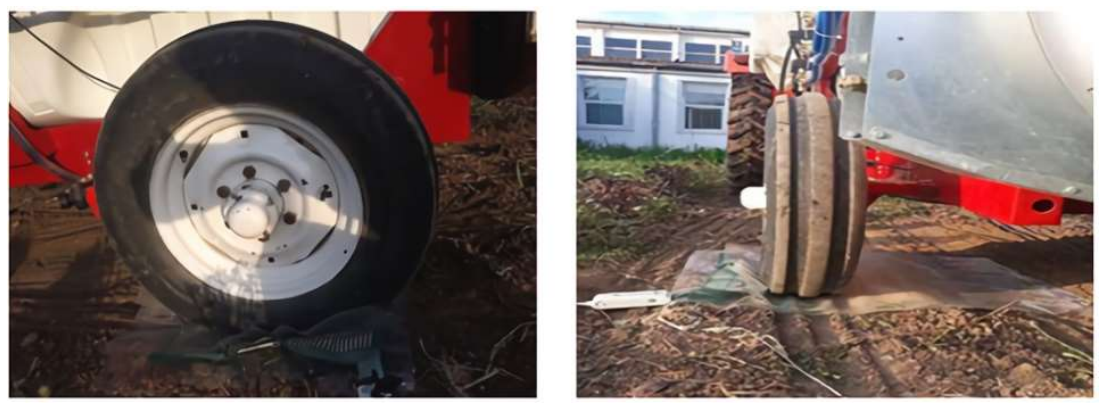

Fig. 6. Testing with wheel load of $4.9 \mathrm{kN}$ and tire inflation pressure of $100 \mathrm{kPa}$

\section{Results and discussion}

Results were analysed with the I-Scan software, which records the pressure distribution in the footprint, the individual values and the graphical variation over time of the contact area, the contact pressure, maximum pressure recorded, force on the soil, etc.

Data for both analysed input and output parameters are presented in Table 1. 
Table 1. Data recorded with the pressure sensor under the wheel of the MSL sprayer.

\begin{tabular}{|c|c|c|c|}
\hline $\begin{array}{c}\text { Tire inflation } \\
\text { pressure }(\mathrm{kPa})\end{array}$ & $\begin{array}{c}\text { Wheel load } \\
(\mathrm{kN})\end{array}$ & $\begin{array}{c}\text { Contact area } \\
\left(\mathrm{m}^{2}\right)\end{array}$ & $\begin{array}{c}\text { Contact } \\
\text { pressure }(\mathrm{kPa})\end{array}$ \\
\hline 100 & \multirow{5}{*}{2.45} & 0.0315 & 78 \\
\hline 150 & & 0.0243 & 101 \\
\hline 200 & & 0.0210 & 117 \\
\hline 250 & & 0.0203 & 121 \\
\hline 300 & & 0.0184 & 133 \\
\hline 100 & \multirow{5}{*}{4.90} & 0.0288 & 170 \\
\hline 150 & & 0.0229 & 214 \\
\hline 200 & & 0.0218 & 225 \\
\hline 250 & & 0.0188 & 261 \\
\hline 300 & & 0.0177 & 277 \\
\hline 100 & \multirow{5}{*}{7.36} & 0.0422 & 175 \\
\hline 150 & & 0.0417 & 177 \\
\hline 200 & & 0.0377 & 195 \\
\hline 250 & & 0.0358 & 206 \\
\hline 300 & & 0.0349 & 211 \\
\hline 100 & \multirow{5}{*}{9.81} & 0.0619 & 159 \\
\hline 150 & & 0.0546 & 180 \\
\hline 200 & & 0.0539 & 182 \\
\hline 250 & & 0.0513 & 191 \\
\hline 300 & & 0.0481 & 204 \\
\hline 100 & \multirow{5}{*}{12.26} & 0.0602 & 204 \\
\hline 150 & & 0.0541 & 227 \\
\hline 200 & & 0.0525 & 234 \\
\hline 250 & & 0.0509 & 241 \\
\hline 300 & & 0.0463 & 265 \\
\hline
\end{tabular}

The variations of the contact area were plotted, under the influence of the three factors: tire inflation pressure, wheel load and the contact pressure.

Figure 7 shows the variation of the contact area at variable wheel loads and constant tire inflation pressures. The contact area increases approximately linearly, proportional to the increase in wheel load, disregarding tire inflation pressure.

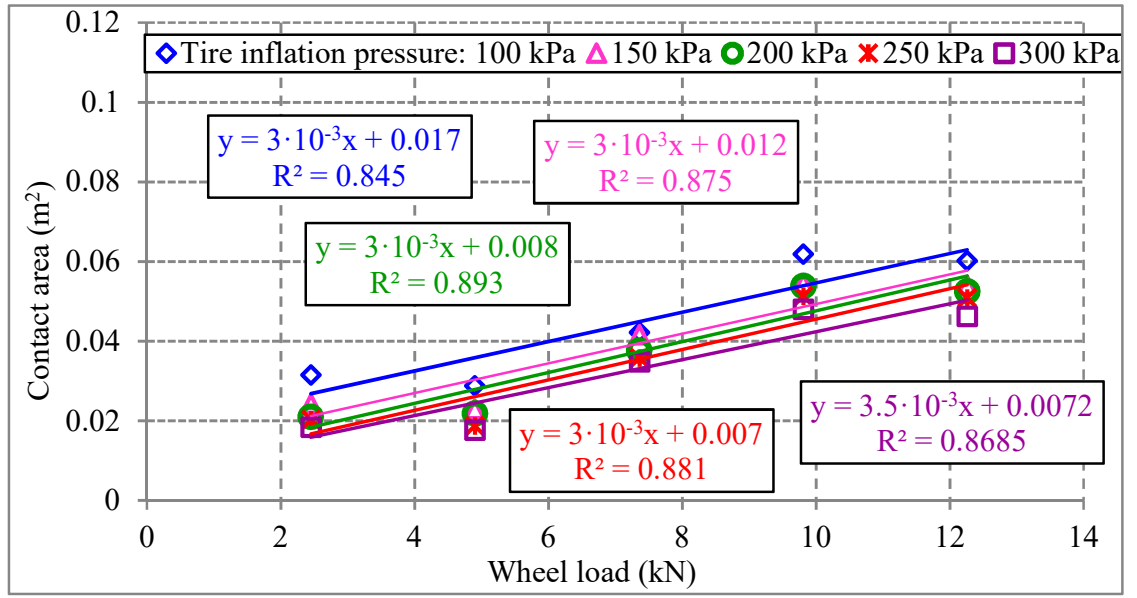

Fig. 7. Changes in MSL sprayer-soil contact area, for variable wheel loads and constant tire inflation pressures 
There is a large correlation of experimental data with the linear variation law (over 0.845 in all analysed cases), showing that the contact area is directly proportional to the wheel load increase. At the lowest wheel load $(2.45 \mathrm{kN})$ the contact area is about 0.0184 $0.0315 \mathrm{~m}^{2}$, and these values increase to $0.0436-0.0602 \mathrm{~m}^{2}$ for $12 \mathrm{kN}$ load and for $100-300$ $\mathrm{kPa}$ tire inflation pressures. The regression lines are not perfectly parallel, so they do not have the same slope, but this lack of parallelism can be due to the specific testing conditions (the appearance and geometry of the tire, tire stiffness or elasticity, and also by the intersection of the sensitive lines of the sensor with the ribs of tire). If the variation of the contact area is proportionally increasing with the wheel load, it is proportionally decreasing with the tire inflation pressure.

The variation of the contact area in relation to variable tire inflation pressure, for constant wheel load, is presented in Figure 8. If the tire inflation pressure increases, the contact area decreases proportionally with it, but the decrease is insignificant. The values follow exponential and power distribution laws, with high correlation coefficients $\left(\mathrm{R}^{2}=\right.$ $0.942-0.977)$. The regression curves follow a certain parallelism.

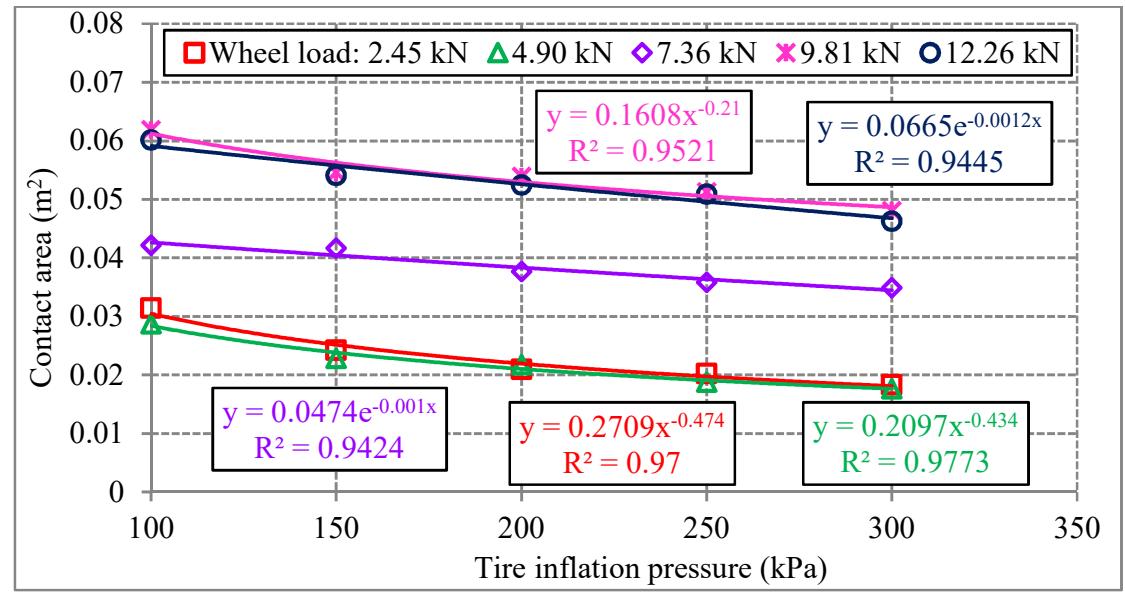

Fig. 8. Changes in MSL sprayer-soil contact area, for variable tire inflation pressures and constant wheel loads

At the variation of contact area with variable tire inflation pressure at constant wheel loads, the range of contact area values is wider. At $100 \mathrm{kPa}$ tire inflation pressure, the contact area increases almost twice, from $0.0315 \mathrm{~m}^{2}$ at $2.45 \mathrm{kN}$ load to about $0.0602 \mathrm{~m}^{2}$ for $12.26 \mathrm{kN}$ wheel load.

Figure 9 shows the changes in tire-soil contact area depending on the contact pressure, for five wheel load values. It was obtained a perfect correlation of experimental data with the power variation law $\left(\mathrm{R}^{2}=0.999-1\right)$. The variation curves are distinctive and in a relatively wide range of values. For $2.45 \mathrm{kN}$ load, the regression line is found in the left bottom corner (due to low values of contact area and contact pressure). The range of contact areas for $12.26 \mathrm{kN}$ load are placed in the upper right corner of the graph with a wide range of contact areas and contact pressures (both of them have higher values). Even though the contact pressure domains overlap partially for the filled tank, it can be noticed that the contact area values are relatively distinct. The contact pressure varies between 78$133 \mathrm{kPa}$ for $2.45 \mathrm{kN}$ wheel load, being related to contact areas of $0.0184-0.0315 \mathrm{~m}^{2}$, and these domains become wider for higher wheel loads. 


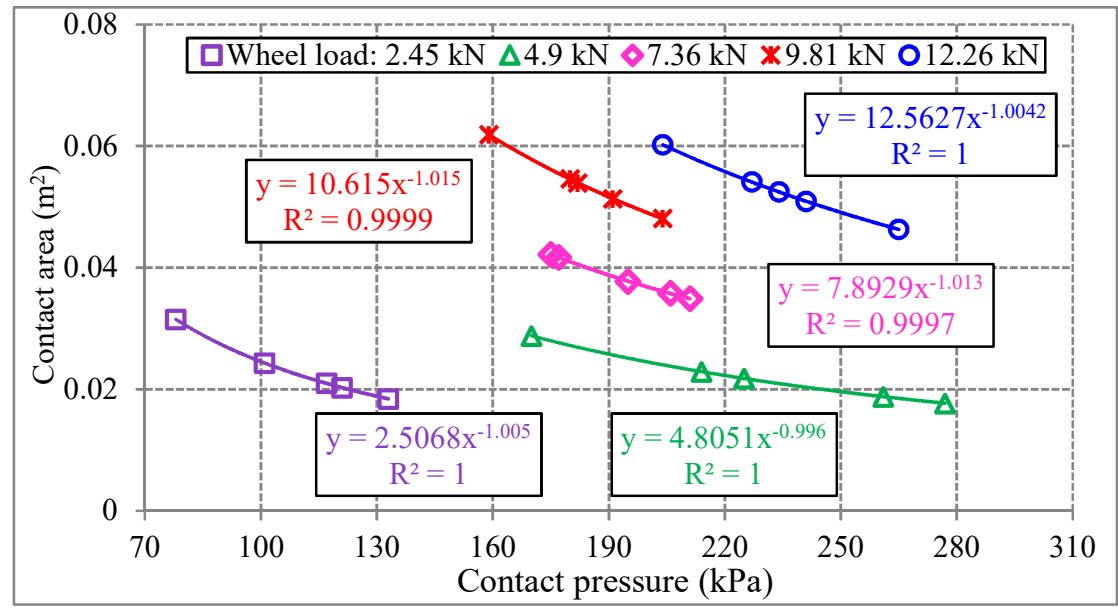

Fig. 9. Contact area variation with MSL tire-soil contact pressure and wheel load

Thus, at $12.26 \mathrm{kN}$ load, for contact pressures of $204-265 \mathrm{kPa}$, contact areas are between 0.0463-0.0602 $\mathrm{m}^{2}$, with smaller values at higher contact pressure. All regression curves have a slightly downward slope, the values of this slope being similar from one wheel load to another (the regression curves are approximate symmetrical).

Figure 10 shows the variation of the contact pressure with tire inflation pressure for the tested wheel loads. The regression curves have an increasing slope and are slightly parallel, except for the curve corresponding to the wheel load of $4.9 \mathrm{kN}$. The best correlation of the experimental data with the force type variation law was obtained for wheel load of $4.9 \mathrm{kN}$, where the correlation coefficient had a high value $\left(\mathrm{R}^{2}=0.9775\right)$.

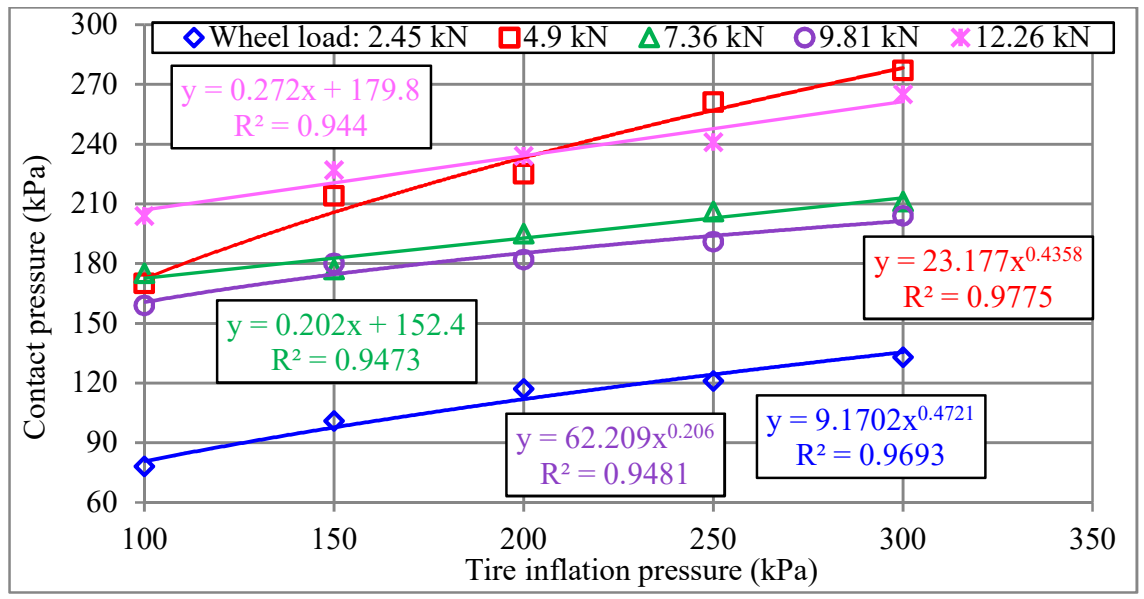

Fig. 10. Changes in contact pressure due to variable tire inflation pressure and constant wheel load

Figure 11 shows the variation of footprints obtained during testing and the distribution of contact pressure, with maximum values recorded in the area of the tire edges. The contact pressure is computed as the average of the pressures recorded by each sensitive element of the Tekscan Industrial Sensing pressure sensor which was in contact with the tire during testing. Studying the footprints, the tendency is obvious: the increase in tire inflation pressure results in decreased contact area. As wheel load is distributed in a smaller surface, an increase in the contact pressure is obtained. 


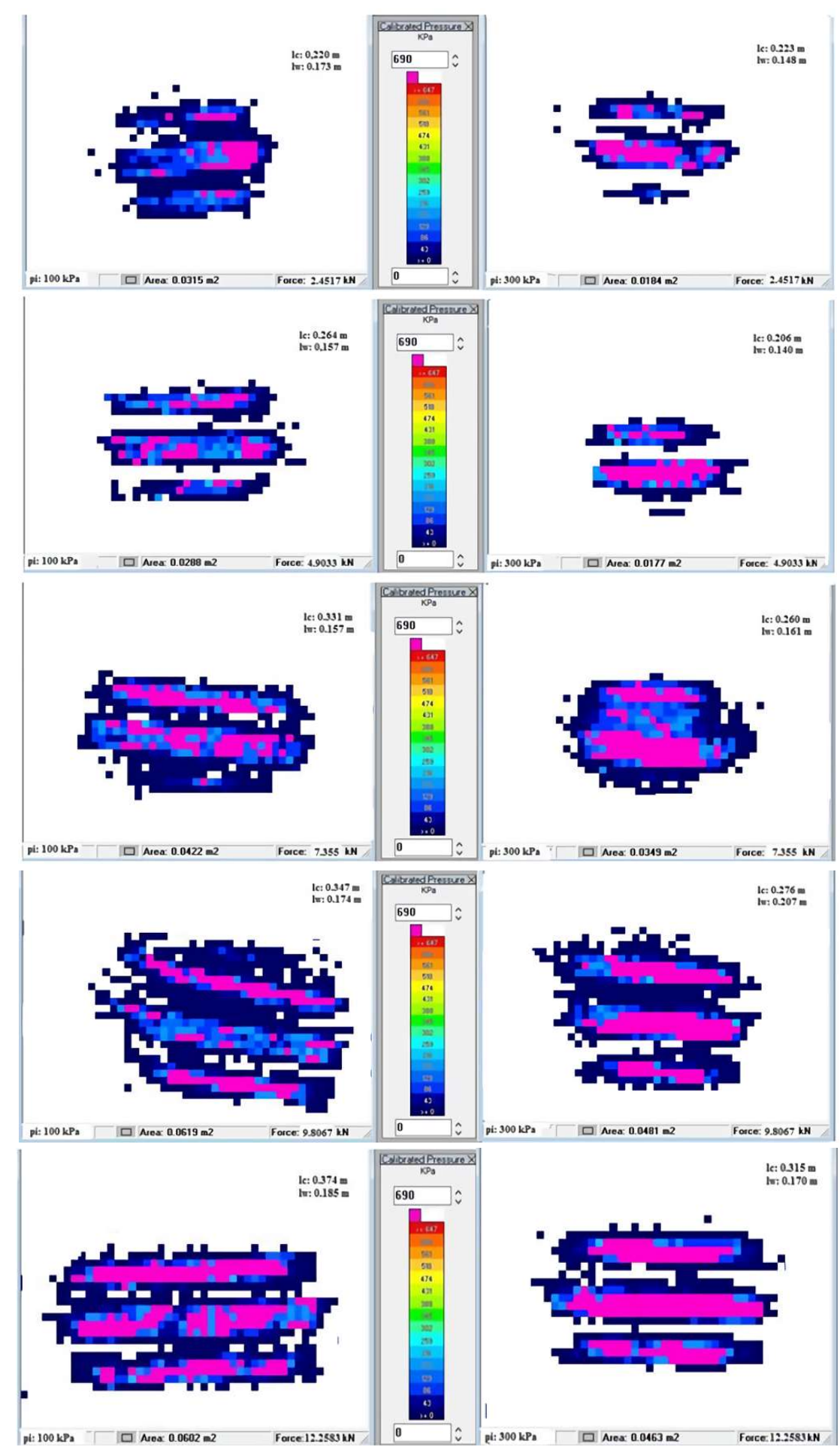

Fig. 11. Changes in footprint shape during testing with increasing wheel loads (tire inflation pressure: left side $-100 \mathrm{kPa}$, right side $-300 \mathrm{kPa}$ ) 
Also, as wheel load increases, under constant tire inflation pressures, a significant increase in contact area was achieved. At $100 \mathrm{kPa}$ tire inflation pressures, the contact area increased almost three times, from about $0.184 \mathrm{~m}^{2}$ for a load of $2.45 \mathrm{kN}$ to about $0.0463 \mathrm{~m}^{2}$ for wheel load of $12.26 \mathrm{kN}$. Footprint shape also changed visible during the tests. If at the minimum wheel load $(2.45 \mathrm{kN})$ and tire inflation pressure $(100 \mathrm{kPa})$ the footprint is somewhat elliptically-shaped, at the same tire inflation pressure but at maximum wheel load $(12.26 \mathrm{kN})$, the shape of footprint tends to become rectangular. If wheel load is kept constant, and the tire is inflated with minimum tire pressure, the footprint is rectangular; increasing the tire inflation pressure leads to the decrease of contact area, and also in a change of footprint shape. At low wheel load the shape of the footprint is elliptical, and at high wheel load the footprint becomes rectangular shaped with slightly spherical corners.

\section{Conclusions}

When using higher tire inflation pressures during soil works, farmers will get smaller contact areas and as a result, soil deformation will increase and stresses will be distributed to greater depths. The ideal situation is to use low tire inflation pressures, because thus the tires will deform more, contact area will be larger, contact pressure will be lower, soil deformation will be lower and the stresses will will be distributed at lower depths.

Unless the case of wheel load of $2.45 \mathrm{kN}$ and the tire inflation pressure of $100 \mathrm{kPa}$, in all other situations, contact pressures higher than $80 \mathrm{kPa}$ have been obtained, which means that in all these cases the agricultural soil will be compacted. In the analyzed cases, subsoil compaction (0.3-0.4 m depth) occurs only when the spraying machine tank is filled with liquid. With empty tank, the sprayer would only cause topsoil compaction. However, proper management practices, such as choosing the lightest sprayer, maintaining proper tire inflation pressure, monitoring soil moisture, using the same tracks and limiting unnecessary passes over a field can reduce compaction risks when applying phitosanitary treatments.

\section{Acknowledgement}

This work was supported by a grant of the Romanian Research and Innovation Ministry, through Programme 1 - Development of the national research-development system, subprogramme 1.2 - Institutional performance - Projects for financing excellence in RDI, contract no. 16PFE.

\section{References}

1. European Academies Science Advisory Council (EASAC). Policy report 36. Opportunities for soil sustainability in Europe. ISBN: 978-3-8047-3898-0 (2018)

2. K.Ç. Selvi, M. Sağlam, O. Dengiz, Geostatistical approach to determine the effects of different soil tillage methods on penetration resistance in a clayey soil. INMATEH Agricultural Engineering 52 (2): 19-26 (2017)

3. M.F. Nawaz, G. Bourrié, F. Trolard, Soil compaction impact and modelling. A Review, Agron. Sustain. Dev. Springerlink (2012)

4. Y. Tekin, B. Kul, R. Okursoy, Sensing and 3D mapping of soil compaction, Sensors 8: 3447- 3459 (2008)

5. S.Șt. Biriș, V. Vlăduț, Use of Finite Element Method to determine the influence of land vehicles traffic on artificial soil compaction, Book: Water Stress 1: 179-198, $1^{\text {st }}$ Edition, Editors: Ismail Md. Mofizur Rahman and Hiroshi Hasegawa. InTech Publishing. Rijeka, Croaţia (2012)

6. M.A. Hamza, W.K. Anderson, Soil compaction in cropping systems. A review of the nature, causes and possible solutions. Soil \& Tillage Research 82: 121-145 (2005) 
7. A. Alaoui, E. Diserrens, Mapping soil compaction - a review, Current Opinion in Environmental Science \& Health 5: 60-66 (2018)

8. Annual report on the state of the environment in Romania, 2017. National Agency for Environmental Protection, Bucharest (2018)

9. S.Șt. Biriș, N. Ungureanu, D. Cujbescu, Modelling of soil compaction under heavyduty tractors. INMATEH - Agricultural Engineering 57 (1): 261-270 (2019)

10. S.Şt. Biriş, N. Ungureanu, E. Maican, G. Paraschiv, Gh. Voicu, M. Manea, FEM model for the study of interaction between the driving wheel and the rolling track for agricultural land vehicles. Proceedings of the $39^{\text {th }}$ International Symposium „Actual Tasks on Agricultural Engineering", 95-106 (2011)

11. T. Batey, Soil compaction and soil management - a review, Soil Use and Management 25: 335-345 (2009)

12. K. Xia, Finite element modeling of tire/terrain interaction: Application to predicting soil compaction and tire mobility, Journal of Terramechanics 48: 113-123 (2011)

13. S.Şt. Biriş, L. Savin, N. Ungureanu, E. Maican, V. Vlăduţ, I. Ganea, I.L. Caba, Researches on the use of Finite Element Method to optimize the wheel tyres exploitation for agricultural vehicles. INMATEH - Agricultural Engineering 39 (1): 5-12 (2013)

14. J. Arvidsson, T. Keller. Soil stress as affected by wheel load and tyre inflation pressure. Soil Till. Res. 96: 284-291 (2007)

15. T. Keller, M. Lamandé, S. Peth, M. Berli, J.Y. Delenne, W. Baumgarten, W. Rabbel, F. Radjaï, J. Rajchenbach, A.P.S. Selvadurai, D. Or, An interdisciplinary approach towards improved understanding of soil deformation during compaction. Soil \& Tillage Research 128: 61-80 (2013)

16. J.J.H. Van den Akker, T. Hoogland, Comparison of risk assessment methods to determine the subsoil compaction risk of agricultural soils in The Netherlands. Soil \& Tillage Research 114: 146-154 (2011)

17. Fountas S., Paraforos D., Cavalaris C., Karamoutis C., Gemtos T., Abu-Khalaf N., Tagarakis A., A five-point penetrometer with GPS for measuring soil compaction variability. Computers and Electronics in Agriculture 96: 109-116 (2013)

18. N. Lozano, M.M. Rolim, V.S. Oliveira, U.E. Tavares, E.M.R. Pedrosa, Evaluation of soil compaction by modelling field vehicle traffic with SoilFlex during sugarcane harvest. Soil \& Tillage Research 129: 61-68 (2013)

19. G.F. Botta, A. Tolon Becerra, F. Bellora Tourn, Effect of the number of tractor passes on soil rut depth and compaction in two tillage regimes. Soil \& Tillage Research 103: 381-386 (2009)

20. V. Vlăduț, M. Matache, S. Bungescu, Ș.Șt. Biriș., The determination of soil deformations as a result of the applied pressure by the tractors rolling parts and the auto propelled agricultural machines. Scientific Papers, Faculty of Agriculture, USAMVB Timişoara 40 (2): 505-512 (2008)

21. Y. Tekin, R. Okursoy, Development of a hydraulic-driven soil penetrometer for measuring soil compaction in field conditions. Journal of Applied Sciences 7: 918-921 (2007)

22. B. Badalikova, Influence of Soil Tillage on Soil Compaction. Chapter in book In: Soil Engineering, Soil Biology, Amity University Uttar Pradesh, Noida, UP, India, 20 (230): 19-30 (2010)

23. D. Wulfsohn, Soil-tire contact area. Advances in Soil Dynamics. ASABE 3: 59-84 (2009)

24. https://www.discounttire.com/store-locator (accessed 15.04.2019)

25. Contact patch - the risks due to under and over inflation, https://www.tyreleader.co.uk/tyres-advices/tyre-contact-patch (accessed 15.04.2019) 